\title{
Research on Rural Highway Project Construction Management and Maintenance
}

\author{
Fei Shan* \\ Xi'an Shiyou University, Xi'an 710065, Shaanxi Province, China \\ *Corresponding author: Fei Shan, mma0405@sina.com
}

\begin{abstract}
In this paper, combined with an actual case project, activity-based costing is used to analyze the labor costs, material costs, and the corresponding indirect costs (such as site management fees and taxes) where each cost is analyzed in detailed. Through quantitative comparison, it further determines which business activities are the key cost control objects and proposes targeted implementation plans for actual cost management in the future in order to provide new ideas for improving the implementation efficiency in addition to a reasonable cost control of highway engineering projects. At the same time, through analyzing the situation of highways, different maintenance modes are compared to put forward a more perfect rural road maintenance and management mode.
\end{abstract}

Keywords: Highway construction; Cost management; Activity-based costing; Highway maintenance

Publication date: August 2021; Online publication: August 30, 2021

\section{Introduction}

Rural areas do not have the advantage of location in economic development. The main reason is because Jiatong is relatively closed so improving the rural road infrastructure is of great significance to promote the integration of urban and rural economy ${ }^{[1]}$. The highway construction in Nongguan has always been the focus of the government's work. The government has given substantial financial and policy support to push the development of rural construction in this good environment ${ }^{[2]}$. This paper selects the activity-based costing method and combines with the characteristics and cases of rural roads to specify a targeted plan for the maintenance and management of rural roads.

\subsection{Case background}

A highway is located at the new rural area, which mainly focuses on tourism. The construction of this avenue is conducive to the rapid development of the local economy. The ground structure of the avenue is mainly asphalt mixtures. The basic parameters of the ground structure are as follows: the upper layer is fine sand asphalt concrete; the middle layer and the whole surface layer are made up of medium grain asphalt concrete; the bottom layer is coarse grain asphalt concrete. The basic structure uses concrete to further stabilize the gravel.

\subsection{Operation calculation}

\subsubsection{Determining the cost accounting plan}

New construction projects should be carried out in accordance with the normal construction process and the production process of engineering construction, where the asphalt concrete paving construction must be carried out in detailed ${ }^{[3]}$. It can be divided into asphalt concrete mixing, transportation, on-site paving, 
rolling and maintenance, as well as other engineering construction procedures. It can divide the activitybased cost evaluation target and process to implement the actual cost of resources and establish a set of cost accounting system for basic data information, such as cost control, cost calculation, and cost management [4]. The construction project cost budget of enterprises after bidding includes the total raw material consumption table of the new project, industrial equipment demand table, machinery rental amount, subcontract of the new project construction, project construction schedule, procurement plan of various raw material resources, and basic raw materials required for the cost control of the construction project ${ }^{[5]}$.

\subsubsection{Cost collection and distribution}

\subsubsection{Labor cost management}

The labor cost from project construction activities is also a key component of a project, and it fluctuates with the market situation. First, according to the construction progress, natural environment, and characteristics of the construction process, excellent prediction and analysis of the total number of labors on the construction site should be done for data analysis ${ }^{[6]}$. By strengthening the budget management of roads and specifying a more reasonable labor plan, labor waste can be effectively reduced to save costs. In the implementation process of different highway projects, there are different construction schemes at different stages. Even if there is more financial support for rural roads, market-oriented management should be used to further reduce the cost. In the construction process, all personnel should be targeted for management and allocation.

\subsubsection{Material cost management}

In the process of material cost management of highway engineering projects, there are often some problems, such as weak cost concept, insufficient analysis of the market situation, poor material quality, and so on. Therefore, the control of material cost needs to follow the important principle of combining economic benefits with safety benefits. On the one hand, the management of suppliers should be strengthened, mutual benefits and win-win results should be achieved, and a stable cooperative relationship should be established. On the other hand, it is necessary to strengthen the management of site engineering materials, including the control of quantity and quality to avoid material waste and to save cost.

\subsubsection{Mechanical equipment cost management}

The cost of machinery and equipment in engineering construction projects is sometimes close to half of the cost of the engineering construction in which it is also the key to the cost management of engineering construction. Therefore, in engineering construction work, there must be strict requirements for the cost of industrial equipment while the daily maintenance system log of engineering machinery and equipment needs to be done well in the whole process of construction. The cost of mechanical equipment includes purchase cost, maintenance cost, and repair cost. In order to control the purchase cost, excellent early planning is required in addition to establish an effective mechanical equipment management system according to the specific requirements of the construction scheme. On the other hand, the control of the maintenance cost is an important way to save money, so it is necessary to assemble special maintenance personnel, keep maintenance records, and take appropriate measures to provide work enthusiasm in improving the efficiency of maintenance work.

\subsubsection{Water and electricity cost management}

Engineering construction projects consume a lot of water and electricity during the whole construction process. The hydropower cost that is incurred during the construction of new projects should be evenly 
distributed. At the end of each month, according to the hydropower cost required by new project constructions, data analysis and search are carried out to develop a better management method for new projects of engineering construction work in the future.

\subsubsection{Construction site change and visa}

In the whole process of engineering construction, there are new projects and design plans are sometimes inconsistent, so it is necessary to carry out engineering changes. At times, engineering changes would increase the bill of quantities or reduce the content of engineering items. For project content upgrade due to project change, site visa work will be carried out and relevant procedures would be completed. The effective measures to strengthen the management of design change and engineering visa include organizational measures, technical measures, economic measures, and contract measures. Organizational measures are systems used to clarify the responsibilities of personnel. Technical measures refer to the situation where the design scheme and construction scheme do not conform to the site conditions in order to reduce the situation where parties shirk responsibility or a delay in the construction. Economic measures refer to the following: when dealing with claims and delay compensation visa, relevant procedures should be strictly followed in addition to reasonably divide the rights and responsibilities as well as compensation. Contract measures are the most critical measures in which contract problems should be taken seriously and visa changes should be dealt accordingly.

\subsubsection{Construction site management fee management}

On-site expenses of construction enterprises mainly refer to the expenditure of the construction site to strengthen the organization construction and management means in addition to the sales expenditure of construction enterprises to raise funds for production, processing, and manufacturing theme activities. In terms of the construction site management, only by doing well in resource allocation, the effective connection between the engineering design and the construction site can be realized. Whether it is manpower, materials, or mechanical equipment, its reasonable configuration can ensure an orderly operation of the construction site.

\subsubsection{Total cost calculation of subgrade works}

\subsubsection{Direct engineering cost management calculation}

The cost of each subproject under the new project of direct engineering cost construction work is accumulated. The selection and mixing of raw materials are involved in the first step. Transportation to the construction site is the second step. Site spreading and rolling belong to the third step. The fourth step is to maintain a mixture of healthy and open transportation.

The direct engineering cost of a new engineering construction project $=$ the direct labor cost in the process of each subproject + the direct labor cost in the process flow of each subproject + the immediate mechanical equipment cost in each process.

\subsubsection{Direct labor cost in the process of each subproject}

The labor price in the bidding evaluation method is multiplied by the total labor cost (Table 1). 
Table 1. Labor cost of each process

\begin{tabular}{ccccc}
\hline Quota name & Corresponding resources & $\begin{array}{c}\text { Pre-measurement } \\
\text { (piece) }\end{array}$ & $\begin{array}{c}\text { Estimated consumption } \\
\text { (yuan, hour) }\end{array}$ & Budget (yuan) \\
\hline \multirow{2}{*}{ Types of work } & Auxiliary type of work & 4 & 73 & 635 \\
required by stall & Ordinary type of work & 30 & 609 & 5,176 \\
assistant & Technical type of work & 3 & 52 & 4,643 \\
& - & - & - & 10,454 \\
\hline
\end{tabular}

\subsubsection{Calculation of material cost for operation procedure}

The total amount of raw materials required for the construction site of the new engineering construction project is mainly the raw materials required for the solid line project calculated according to the construction documents (Table 2).

Table 2. Construction project material cost

\begin{tabular}{ccccc}
\hline Quota name & Material science & Budget $(\mathrm{T})$ & Unit price (yuan / T) & Budget amount \\
\hline & Asphalt & 308 & 500 & 154,000 \\
Asphalt concrete & Crushed stone & 5,418 & 56 & 303,408 \\
material science & Sand & 214 & 53 & 11,342 \\
& Mineral powder & 256 & 104 & 26,624 \\
& - & - & - & 495,374 \\
\hline
\end{tabular}

\subsubsection{Direct cost of construction machinery and equipment calculation}

At the present stage, the cost of construction machinery and equipment in new projects accounts for a large proportion of the construction cost, mainly the direct cost of construction analysis. The cost of construction machinery and equipment is mainly composed of the total number of construction machinery conversion and machinery price. In order to obtain the total cost of construction machinery, the role of engineering expenditure should be considered (Table 3).

Table 3. Construction machinery cost

\begin{tabular}{|c|c|c|c|c|c|}
\hline Quota name & Equipment name & $\begin{array}{l}\text { Required quantity } \\
\text { (set) }\end{array}$ & $\begin{array}{c}\text { Unit price (unit } \\
\text { hour / yuan) }\end{array}$ & Budget volume & Budget amount \\
\hline \multirow{5}{*}{$\begin{array}{l}\text { Paving and } \\
\text { rolling } \\
\text { mechanics }\end{array}$} & Mixing machine & 1 & 526 & 26 & 13,676 \\
\hline & Supply vehicle & 1 & 82 & 24 & 18,768 \\
\hline & truck & 3 & 67 & 72 & 4,824 \\
\hline & Roller & 3 & 196 & 74 & 14,504 \\
\hline & Tire roller & 2 & 156 & 46 & 7,176 \\
\hline - & - & - & - & - & 58,948 \\
\hline
\end{tabular}

\subsubsection{Construction site management cost calculation}

The key to the cost of the project department during the construction of the new project site is the various insurance premiums of the construction site, as well as the various expenses of the project manager and staffs of the new project construction. This includes the salary of on-site technicians, property application fees, and office expenses. The construction site management method also includes indirect expenses, which 
is mainly based on the indirect expenses payment specification.

In order to allocate effectively, it is also necessary to consider the difficulty of the new construction project, the progress of the new construction project, the generation of the use value of the sub project, and the consumption of various resources. Specifically, the determination of construction site management cost is a comprehensive balance result. It is an overall estimation according to the difficulty, progress, value, and resource consumption of the project. At the same time, it is necessary to have a flexible adjustment scheme to deal with the sudden and complex construction site situation (Table 4).

Table 4. Construction cost of asphalt concrete surface course

\begin{tabular}{|c|c|c|c|c|c|c|}
\hline Quota name & $\begin{array}{c}\text { Cost of } \\
\text { operation } \\
\text { activities }\end{array}$ & Employment name & $\begin{array}{c}\text { Budget quantity } \\
\text { (person or set) }\end{array}$ & $\begin{array}{c}\text { Unit price } \\
\text { (yuan / } \mathrm{h} \text { or } \mathrm{T})\end{array}$ & $\begin{array}{l}\text { Planned } \\
\text { quantity } \\
(\mathrm{h} \text { or T) }\end{array}$ & $\begin{array}{l}\text { Budget } \\
\text { amount }\end{array}$ \\
\hline \multirow{7}{*}{$\begin{array}{c}\text { Asphalt } \\
\text { concrete } \\
\text { mixing }\end{array}$} & \multirow{3}{*}{$\begin{array}{l}\text { Mixing and } \\
\text { division cost }\end{array}$} & Group leader & 1 & 8.4 & 46 & 36 \\
\hline & & Ordinary workers & 15 & 8.3 & 306 & 2,314 \\
\hline & & Total & & & & 2,377 \\
\hline & \multirow{4}{*}{ Mixer fee } & Shippers & 5 & 115 & 88.2 & 9,435 \\
\hline & & Concrete mixing plant & 1 & 415 & 86.5 & 35,673 \\
\hline & & $\begin{array}{l}\text { Power generation } \\
\text { equipment }\end{array}$ & 3 & 343 & 24 & 7,213 \\
\hline & & Subtotal & & & 46 & 52,321 \\
\hline \multirow{3}{*}{$\begin{array}{l}\text { Asphalt } \\
\text { concrete } \\
\text { transport } \\
\text { machinery }\end{array}$} & \multirow{3}{*}{$\begin{array}{c}\text { Transportation } \\
\text { equipment } \\
\text { cost }\end{array}$} & Mixing total & & & & 54,698 \\
\hline & & 25-ton tank car & 15 & 0.44 & 87,086 & 38,700 \\
\hline & & Transportation subtotal & & & & 38,700 \\
\hline \multirow{15}{*}{$\begin{array}{l}\text { Asphalt } \\
\text { concrete } \\
\text { paving and } \\
\text { rolling }\end{array}$} & \multirow{4}{*}{$\begin{array}{l}\text { Auxiliary } \\
\text { labor cost }\end{array}$} & Assistant worker & 4 & 7.8 & 65 & 489 \\
\hline & & Ordinary workers & 30 & 7.9 & 587 & 4,435 \\
\hline & & Technician & 3 & 7.5 & 430 & 345 \\
\hline & & Subtotal & & & & 5,269 \\
\hline & \multirow{6}{*}{$\begin{array}{l}\text { Conveying } \\
\text { roller } \\
\text { equipment } \\
\text { cost }\end{array}$} & Pump truck & 1 & 406 & 20 & 8,634 \\
\hline & & Come on, Chen & 1 & 69 & 19 & 1,378 \\
\hline & & Traffic vehicles & 3 & 61 & 67 & 3,631 \\
\hline & & Steel wheel roller & 3 & 189 & 68 & 12,783 \\
\hline & & Caster roller & 3 & 153 & 40 & 5,878 \\
\hline & & Subtotal & & & & 32,304 \\
\hline & \multirow{5}{*}{ Raw material } & Asphalt raw material & & 210 & 4,008 & 841,680 \\
\hline & & Crushed stone material & & 4,330 & 47 & 203,510 \\
\hline & & Sand & & 196 & 43 & 8,428 \\
\hline & & Mineral powder & & 252 & 87 & 21,924 \\
\hline & & Subtotal & & & & $1,075,542$ \\
\hline \multirow{3}{*}{\multicolumn{2}{|c|}{ Other expenses }} & Site management fee & & & & 50,823 \\
\hline & & Taxes & & & & 67,172 \\
\hline & & Total other expenses & & & & 117,995 \\
\hline
\end{tabular}




\subsubsection{Tax management}

According to the construction period, the subproject will be completed in July. The bill of quantities of the new project is $42546 \mathrm{~m}^{3}$, and the price in the tender offer is 46.3 yuan $/ \mathrm{m}^{3}$. Therefore, the gross output value in the bill offer is $1,969,879$ yuan. The tax rate required by the state is $3.41 \%$, which includes valueadded tax and surtax (simple collection). The gross domestic product in July that needs to pay tax to the state is $42,546 \times 46.3 \times 3.41 \%=67,172$ yuan.

\subsubsection{Management advantages}

The new project activity cost accounting method can clearly distinguish the responsibilities of each work stage, raw material application, and indirect cost application. It is also able to conduct data analysis on related costs to clearly know which work theme activities belong to key management methods, primary, and secondary stages. In the process of project construction, it is necessary to carry out the operation of key management methods and key steps while making the plan for the related project construction management process. In the process of project construction, the activity-based cost accounting method is more conducive to the organization and manipulation of work activities where the allocation of indirect costs is more effective than before while the research on construction cost is more scientific and in line with the specific situation.

\section{Highway maintenance}

At present, the main problems of rural highway maintenance and management include imperfect management system and measures, incomprehensive management and maintenance consciousness, difficult financing and investment, and lack of professional talents. In order to establish the rural highway management mechanism, it is necessary to grid the rural highway management, establish a maintenance and management network with special departments as professional guidance, have local government supervision and liaison, real-time monitoring of rural highway administration, as well as realize regional management linkage through professional command, resource sharing, fund transfer, and human resource scheduling. It is also necessary to further strengthen the actual work efficiency of rural highway management and maintenance departments in addition to enhance the comprehensive ability of grass-roots departments to manage and maintain roads.

\subsection{Strengthening the main responsibility}

In order to strengthen the main responsibility of rural highway management, there is a need to upgrade the rural construction system to the government level as well as promote the people and governments at all levels to fulfill the main responsibility of rural highway maintenance and management in strict accordance with relevant transportation policies and regulations. In this process, it is then necessary to give full play to the township, where the village committee will play a more important role in the rural construction system, the working mechanism of unified linkage of governments at all levels, the common participation of the masses, as well as the common maintenance.

\subsection{Defining personnel responsibilities}

In the maintenance and management of rural roads, a road maintenance center can be built while making full use of the system reform to strengthen the rural road maintenance and management system. At the county level, the rural roads that are managed by the Public Security Bureau and the Highway Bureau should be integrated and managed by one department or unit. At the rural level, a rural road management 
system should be established, full-time personnel should be assigned to take charge of the organization and leadership of rural road repair, daily maintenance, and security facilities construction, as well as to accept the leadership of township and county-level rural management departments.

\subsection{Formulating management and maintenance mechanism}

Rural roads have the characteristics of many points, wide areas, and long lines, which are closely related to the vital interests of the people. The management and maintenance of rural roads is mainly to build a rural road investment and financing system based on government investment in encouraging social capital and rural participation to provide a strong financial guarantee for the maintenance and management of rural roads. First of all, township organizations should be included in the general public budget, including rural maintenance funds, professional management organizations, and personnel. Secondly, it is necessary to implement relevant policies of highway maintenance and management, clarify the minimum standard for the total amount of public financial management funds used in the daily maintenance of rural roads, broaden the financing channels, and finally actively guide the villagers that live along the road to work for the maintenance of these rural roads. At the same time, it is also necessary to actively encourage enterprises, institutions, and individuals along the road to donate in the form of organizational obligations in supporting equipment, materials, and resources for the maintenance of rural roads.

\subsection{Innovative maintenance mode}

Rural highway maintenance and management should be combined with the actual situation of rural areas to form an innovative maintenance mode through the establishment of management pilot in exploring a set of effective maintenance mode in practice. For example, selecting towns with good foundation for pilot work, implementing the system of rural road maintenance and management, dividing rural roads according to blocks, and adopting sectional maintenance with multi-person contract or family contract for road maintenance and management can effectively reduce the maintenance cost of the government and fully mobilize the rural surplus labor force.

\subsection{Strengthening the management of overloaded vehicles}

Overloaded vehicles greatly damage rural roads, especially rural roads with poor subgrade and pavement quality, which cannot bear the load of these vehicles. In order to strengthen the maintenance of rural roads, it is necessary to strengthen the management of overloaded vehicles. First of all, the management of out of gauge vehicles should be extended to rural roads, and mobile management should be adopted for rural roads with the overload phenomena from time to time. Secondly, according to the regulations of highway safety protection and other relevant documents, the Transportation Bureau, township people, and government should set up necessary height and width limiting facilities at the entrance and exit of township and village roads according to the needs of protecting these roads. Finally, it is necessary to reinforce the punishment of out of gauge vehicles, establish the corresponding information management system, and restrict vehicle drivers who have been repeatedly trained to go on the road.

\subsection{Establishing a security system}

The core of the security system of rural highway maintenance is the system, and the key is the fund. The establishment of a security system is to build a rural highway investment and financing system with government investment as the main part in encouraging social capital and rural participation to provide a strong financial guarantee for rural highway maintenance and management. Firstly, township organizations should be included in the general public budget, where the maintenance funds, management organization 
operation, and basic personnel expenses should be included in the general public budget. Secondly, it is necessary to implement relevant policies of highway maintenance and management and clarify the minimum standard of the total amount of public financial funds in the daily maintenance of rural roads. Finally, it is necessary to broaden financing channels, actively guide villagers that live along the road to work for the maintenance of rural roads, and actively encourage enterprises, institutions, and individuals along the road to support the maintenance of rural roads by organizing voluntary labor, supporting equipment and materials, as well as making voluntary contributions.

\section{Conclusion}

Strengthening the maintenance and management of rural roads, establishing a local road management and maintenance system, and effectively implementing it are important measures to ensure the normal operation of national road network and effectively promote the local economic development. Therefore, it is not only necessary to improve the long-term development of rural road maintenance, but also to improve in terms of local publicity. The local government should use the role of television, radio, newspapers, internet, and other media to widely publicize the important significance and practical role of rural road maintenance so that the cadres and the masses can understand the policy, support the maintenance work, and form an environment where there is concern, support, and supervision of the whole society.

\section{Disclosure statement}

The author declares that there is no conflict of interest.

\section{Author Contributions}

The author investigated the rural highway construction and management related content, as well as wrote the whole article.

\section{References}

[1] Du X, Xu Z, Sheng W, 2009, Improved Ammoniacal-Nitrogen Removal in Non-Planted Vertical FlowConstructed Wetland System by Natural Oxygen Transfer. Fresenius Environmental Bulletin, (10): 1846-50.

[2] Loredo J, Soto J, Ordonez A, et al., 2009, Mercury and Arsenic Pollution Associated to Artisanal Gold Mining in Huanca (Ayacucho Department, Peru). Fresenius Environmental Bulletin, (4): 391-8.

[3] Porter G, 1995, The Impact of Road Construction on Women's Trade in Rural Nigeria. Journal of Transport Geography, (1): 3-14.

[4] Haans J, Westerveld G, 1975, The Application of Soil Survey in the Netherlands. Geoderma, (3): 279 309.

[5] Achour R, Abriak NE, Zentar R, et al., 2014, Valorization of Unauthorized Sea Disposal Dredged Sediments as a Road Foundation Material. Environmental Technology, (13-14): 1997-2007.

[6] Makarachi GA, Tillotson HT, 1992, Road Planning in Rural Areas of Developing Countries. European Journal of Operational Research, (3): 279-87. 